\title{
Study of Physicochemicals Characteristics and Antioxidant Capacity of Cork Oak Acorns (Quercus suber L.) grown in Three Regions in Tunisia
}

\author{
Souad Belghith Igueld ${ }^{1,2^{*}}$, Hatem Abidi ${ }^{1}$, Malika Trabelsi-Ayadi ${ }^{1}$, Jamila K. Chérif ${ }^{1,3}$ \\ ${ }^{1}$ Laboratory Applications of Chemical Resources, Natural Substances and Environment (LACReSNE), Faculty of Sciences of Bizerte, University of \\ Carthage, 7021 Zarzouna-Bizerte, Tunisia. ${ }^{2}$ Preparatory Institute for Engineering Studies of El-Manar B.P.244 El Manar II - 2092 Tunis, Tunisia. \\ ${ }^{3}$ Preparatory Institute for Engineering Studies of Tunis, 2 rue Jawaharlal Nehru, Monfleury, 1008 Tunis, Tunisia.
}

\begin{tabular}{l} 
ARTICLE INFO \\
\hline Article history: \\
Received on: 02/02/2015 \\
Revised on: 15/02/2015 \\
Accepted on: 18/03/2015 \\
Available online: 27/04/2015 \\
\hline Key words: \\
Quercus Suber. L; Minerals; \\
Sugar; DPPH assay; Phenolic \\
content; Flavonoid.
\end{tabular}

\section{INTRODUCTION}

The Cork oak is an evergreen tree of the genus Quercus of the Fagaceae family formerly Cupulifère, it is best known for its thick bark used for making caps. The wood of the cork oak is used as charcoal or firewood due to its considerable calorific value of 7000 cal at $25 \%$ of moisture (Natividade, 1956). In Europe, Asia, North Africa, Middle East, and North America, acorns were once a staple (Brandis, 1972). They are also a valuable food for pets, birds and wildlife. Currently, cork oak acorns (Quercus Suber. L.) are traditionally marketed and consumed in North Africa. When dried and ground into flour, it can be transformed into a paste to use instead of bread, or it is used as a stomachic and antidiarrheal when mixed with honey

\footnotetext{
* Corresponding Author

Souad Igueld Belghith, Preparatory Institute for Engineering Studies of El-Manar, Tunis. Tunisia. Email: sigueld@yahoo.fr
}

(Sijelmassi, 1993). Epidemiological studies in Serbia have suggested that consumption of cork oak acorns may promote general human health (Jevtovic, 1980). Oak kernels (Quercus semen) were traditionally used in medicine, particularly roasted ones (Quercus semen tostum) as astringents, antidiarrhoeals and antidotes (Tucakov, 1971), since it has been established that a diet rich in fruits reduces the risk of cardiovascular diseases, cancer and other diseases caused by oxidative stress. A revaluation of acorns and their use would be desirable. The acorns of all species must be tested and adjusted for their antioxidant activity. Antioxidants are usually used to prevent chronic and degenerative diseases with intermediate scan of free radicals (Rodriguez et al., 2007; Prior and $\mathrm{Gu}, 2005)$. The role of free radical scavenging antioxidants has attracted much attention of not only scientists but also general public, above all, the natural antioxidants contained in fruits, vegetables, spices and dietary supplements (Sies, 2010). Domingues, Ammar et al. and Conde et al. cited several bioactive polyphenols, compounds such as flavonoids, tannins and ellagic 
acid and its diglucoside derivatives that are present in different parts of the cork oak (fruits, leaves and cork) (Domingues, 2009; Ammar et al., 2005; Conde et al., 1998). Flavonoids have not only demonstrated beneficial effects as antioxidants (Garcia-Saura et al., 2005) but also the ability to regulate the expression of adipocytokine gene (Tsuda et al., 2006). Ellagic acid is strongly believed to have antioxidant and antiviral activity. The composition of the cork oak acorns in tocopherol ( $\alpha$-tocopherol and $\beta$-tocopherol) are respectively 38 and $74 \mathrm{mg} . \mathrm{kg}^{-1}$ of dry matter (Cantos et al., 2003). Bainbridges (1986) confirmed that cork oak acorns are rich in carbohydrates, lipids, sterols and amino acids and are low in protein. Rodríguez-Estévez et al. (2008) have enabled to determine the composition of kernels and hulls in minerals, ash, fat, fiber, crude protein. Given the richness of the fruit in antioxidant and given the traditional use of the flour for bread making in parts of North Africa, this fruit can replace in case of famine, some seeds such 69as corn wheat or barley. Therefore, we have undertaken this work to explore antioxidant potential minerals and sugar composition of fruits of cork oak. The influence of harvest location and solvent extract was also studied.

\section{Experimental Section \\ Plant material}

Samples that are subject of this study $(1 \mathrm{~kg})$ were collected during the month of December 2011 in three regions of Tunisia Sejnen (202 m altitude), Nefza (500 m altitude) and Ain Drahem (800 m altitude) located in northern Tunisia. Acorns were cleaned to remove all foreign matter (dust, dirt, immature and damaged fruits). Three batches containing thirty fruits for each region were formed; the hull and kernel of fruit of each batch were then separated and cut into small pieces. All samples were preserved in the dark at a dry place until further use.

\section{Chemical reagents}

The chemical reagent DPPH (2, 2-Diphenyl picrylhydrazyl) and Folin-Ciocalteu phenol were purchased from Sigma Co. (St. Louis, MO, USA). Catechin, gallic acid (98\%) and $\quad \beta$-carotene were from Sigma Aldrich (Steinheim, Germany). Concentrated hydrochloric acid (37\%), absolute ethanol ( $\geq 99.8 \%)$ and absolute methanol $(\geq 99.8 \%)$ were purchased from Panreac Química, S.A. (Barcelona, Spain). Aluminum chloride-6-hydrate $\mathrm{AlCl}_{3} \cdot 6 \mathrm{H}_{2} \mathrm{O}$ (>99\%), sodium nitrite $\mathrm{NaNO}_{2}$ and all other chemical reagents used were obtained from Sigma Co.

\section{Physicochemical characterization}

The moisture content was determined according to the method of Twidwell et al. (2002). The dry matter content was determined in accordance with French standard NF B 51-004 (AFNOR, 1986). A mass of $5 \mathrm{~g}$ of plant material was introduced into a porcelain crucible and dried in an oven at $105{ }^{\circ} \mathrm{C}$ until a constant mass. The mineral matter content in the fruits of the cork oak was determined according to French standard T 211 OM-93. The formol index was evaluated in the fruit extract after soaking overnight. It was determined using the AFNOR method (V. 76102.1985). The titratable acidity was measured by the titrimetric method according to the Tunisian standard NT 52.15 (1982). Titration of free acidity of the aqueous extracts of all cork oak samples was determined by an assay using a sodium hydroxide solution $\mathrm{NaOH}(0.01 \mathrm{M})$ in the presence of phenolphthalein as a color indicator.

\section{Ash content and mineral composition}

The method NF.EN.1482 (March 2003) was used: 5g sample was incinerated with high pressure in a muffle furnace (MLS 1200) for $24 \mathrm{~h}$ at $550{ }^{\circ} \mathrm{C}$. The residue of incineration was extracted with $5 \mathrm{ml}$ of $\mathrm{HNO}_{3} 65 \%$ and $50 \mathrm{ml}$ of water. The mixture was heated a few minutes in a boiling water bath to dissolve the ash. After cooling, the solution was filtered and then placed in a $50 \mathrm{~mL}$ volumetric flask, the volume is adjusted by adding distilled water, where $\mathrm{Fe}, \mathrm{Cu}, \mathrm{Mn}$ and $\mathrm{Zn}$ and other mineral composition were directly measured at the suitable wavelength for each element, using standard solutions for calibration purposes. The concentration of each analyte in the different samples was expressed as mg. $100 \mathrm{~g}^{-1}$ of fresh material from their calibration curves taking into account the dilution factor.

\section{Antioxidant Content \\ Preparation of extracts}

Different solvent systems were used to evaluate the best extraction solvent on the extraction of phenolic compounds: $S_{1}$ methanol/water (80:20, V/V), $\mathrm{S}_{2}$ ethanol/water (50:50, V/V); $\mathrm{S}_{3}$ methanol/acetic acid (99:1). $100 \mathrm{mg}$ of fresh samples were extracted by $10 \mathrm{~mL}$ of different solvents. The supernatant was centrifuged (2500 rev. $\mathrm{min}^{-1}$ ) filtered through Whatman $\mathrm{N}^{\mathrm{o}} 40$ (Whatman International England).

\section{Total Phenolic Content}

The amount of total phenols was determined using the Folin-Ciocalteu reagent according to the method of Singleton and Rossi Jr (1965), and $1 \mathrm{~mL}$ of the extract was added to $5 \mathrm{~mL}$ of distilled water and $1 \mathrm{~mL}$ of $\mathrm{Na}_{2} \mathrm{CO}_{3}(20 \%$; W/V). After $3 \mathrm{~min}, 1$ $\mathrm{ml}$ of the Folin-Ciocalteu reagent was added and mixed. After 30 min of incubation in the dark at $40{ }^{\circ} \mathrm{C}$, the absorbance of all samples was measured at $765 \mathrm{~nm}$ using the Shimadzu UV-Vis spectrophotometer T60U. The results were expressed in terms of mg of equivalent of Gallic acid per gram of sample, using a calibration curve of the gallic acid.

\section{Total Flavonoid Content.}

The total flavonoid content in Quercus Suber was determined according to Zhishen et al (2009) using a method based on the formation of complex flavonoid-aluminium. A volume of $125 \mu \mathrm{L}$ of methanol extract was added to $75 \mu \mathrm{L}$ of a solution of $\mathrm{NaNO}_{2}(5 \% ; \mathrm{W} / \mathrm{V})$. The mixture was left to stand for 6 minutes, then $150 \mu \mathrm{L}$ of a solution $\mathrm{AlCl}_{3} 6 \mathrm{H}_{2} \mathrm{O}(10 \%)$ freshly prepared were added, after 5 min of rest, $500 \mu \mathrm{L}$ of $\mathrm{NaOH}$ (solution $1 \mathrm{M}$ ) was added to mixture. The final volume of the 
solution was adjusted to $2500 \mu \mathrm{L}$ with distilled water. The absorbance was measured at $510 \mathrm{~nm}$ (Shimadzu UV-Vis spectrophotometer T60U). The total flavonoid content of acorn was expressed in terms of catechin equivalent $\left(\mathrm{mg} .100 \mathrm{~g}^{-1}\right)$.

\section{Total Anthocyanin Content}

The total anthocyanin contents were determined according to the procedure of Swain and Hillis (1959). $5 \mathrm{~g}$ of acorn were submitted to extraction with $10 \mathrm{~mL}$ of ethanol $(80 \%$; $\mathrm{V} / \mathrm{V}$ ) for 2 hours with agitation (magnetic stirrer). Then the samples were filtered. The filtrates were completed to a total volume of $10 \mathrm{~mL}$ with $80 \%$ aqueous ethanol. Then $0.02 \mathrm{~mL}$ of $\mathrm{HCl}(37 \%)$ was immediately added. The absorbance was read at 525 and $595 \mathrm{~nm}$ to quantify anthocyanins using the Shimadzu UVVis spectrophotometer T60U. The total anthocyanin contents were quantified according the relation:

$T A=(A 1-A 2) \times 0.879 \times V e \times 2 \times 10 \times F$, where $\mathrm{A}_{1}$ is the absorbance measured at $525 \mathrm{~nm}, \mathrm{~A}_{2}$ measured at $595 \mathrm{~nm}, 0.879$ is the extinction coefficient of anthocyanins. $V e$ : is the total volume recovered after extraction $100 \mathrm{~g}$ sample, and $\mathrm{F}$ is the dilution factor

\section{Determination of total Carotenoid Contents}

The total carotenoid contents were determined according to the procedure described by Rousseff et al. (1987). $200 \mathrm{mg}$ of fresh samples were extracted by $10 \mathrm{ml}$ of acetone-water (80:20; $\mathrm{V} / \mathrm{V}$ ), then allowed to stand for $30 \mathrm{~min}$ at $4{ }^{\circ} \mathrm{C}$. The extract was filtered through Whatman No. 40. The organic phase obtained was extracted repeatedly with hexane $(3 \times 10 \mathrm{~mL})$. The combined extracts were subjected to a rotary evaporator (Laborota 4000 Germany) under reduced pressure at $30^{\circ} \mathrm{C}$. The absorbances of all samples were measured at $450 \mathrm{~nm}$ using the Shimadzu UV-Vis spectrophotometer T60U. The results were expressed in equivalent $\beta$-carotene, compared to a range standard prepared starting from a mother ethanolic solution of $\beta$-carotene.

\section{Evaluation of Antioxidant Activity}

The free radical-scavenging activity was determined using stable 2,2-diphenyl-1-picrylhydrazyl (DPPH') radical according to Brand Williams et al (1995). $2 \mathrm{mg}$ of each sample were dissolved in $1 \mathrm{~mL}$ of methanol. An aliquot of this solution was mixed with $1 \mathrm{~mL}$ of $0.5 \mathrm{mM}$ DPPH in methanol and the final volume adjusted up to $5 \mathrm{~mL}$, so that final concentrations of the samples were in a range from 1,25 to $20 \mu \mathrm{g} \cdot \mathrm{mL}^{-1}$. Then, the mixtures were shaken vigorously and left $30 \mathrm{~min}$ to stand in the dark. The reduction of DPPH radical is accompanied by a color change from violet (DPPH ${ }^{\circ}$ to yellow (DPPH-H). The absorbance of mixture was measured using a spectrophotometer at $517 \mathrm{~nm}$ in a Shimadzu UV-2401 PC spectrophotometer using methanol as blank, after establishing the stationary. One milliliter of $0.5 \mathrm{mM}$ DPPH diluted in $4 \mathrm{~mL}$ of methanol was used as control. The yellow color of solution indicates the end of the reaction. This reduction capacity is determined by a decrease in absorbance induced by free radical inhibitors (Majhenic et al, 2007). Antioxidant activity was expressed as percentage of inhibition in relation to control according to the equation proposed by Yen and Duh (1994): $I(\%)=100 .(A 0-A s) / A 0$, where $\mathrm{A}_{0}$ is the absorbance of the control (containing all reagents except the tested sample), and As is the absorbance of the tested sample. The effectiveness of acorn extracts in scavenging free radicals was evaluated as the concentration of acorn extracts in the reaction mixture that caused a decrease in the initial DPPH concentration by $50 \%$, defined as IC50. These values were calculated from the graph plotting inhibition percentage against extract concentration. 2.6. Sugar content. Soluble sugars were determined by High Performance Liquid Chromatography HPLC method AOAC 98013 982-1 (1990), using a refractive index detector (RID) (Perkin Elmer). The separation was carried out on a SGE SS Exsil amino column $\mathrm{NH}_{2}(150 \times 4.6 \mathrm{~mm}$ I.D.). The elution solvents used were acetonitrile and water $(82: 18 \mathrm{v} / \mathrm{v})$. The column was operated at 25 ${ }^{\circ} \mathrm{C}$ with $1 \mathrm{~mL} / \mathrm{min}$ flow rate. Sample injection volume was $5 \mu \mathrm{L}$. The resultant peak areas in the chromatograms were plotted against calibration curves obtained from multiple standard solutions (external standard method), in a concentration range of 1 $\mathrm{mg} \cdot \mathrm{mL}^{-1}$ for each compound. All the experiments were run in triplicate. The mean values and standard deviations were calculated using the Microsoft Excel software (Microsoft Corporation, Redmond, WA).

\section{RESULTS AND DISCUSSION \\ Physicochemical characteristics}

Some chemical properties of cork used in this study are presented in table 1. As can be seen from these data, the moisture content in the samples ranges from $38 \%$ to $51 \%$. The highest values are those of Ain Drahem where rainfall exceeds $1559 \mathrm{~mm}$ per year. There is the weak acidic character in acorns, the measurable acidity varies between $5.2 \times 10^{-3}$ and $7.1 \times 10^{-3}$ mmol. $\mathrm{L}^{-1}$. The kernels have higher acidity than the hulls. Formaldehyde indexes were similar, however, the lowest value of the acidity and formol index was observed in Sejnan variety. The mineral content of cork fruits is presented in table 2. Based on these results, the fruits are rich in calcium, magnesium, sodium and especially in potassium $\left(6.942 \mathrm{~g} \cdot \mathrm{kg}^{-1}\right)$. Besides potassium, the other minerals are present in the hulls. These results were similar to those reported by Özcan and Bayçu (2005) for potassium content (7.849 ${\left.\mathrm{g} . \mathrm{kg}^{-1}\right)}$ of fruit of the Turkish variety Quercus petraea subsp. Several epidemiological studies have established a link between a diet rich in potassium and a reduced risk of hypertension (Houston and Lanham-New, 2008); stroke and renal calculus (Bazzano et al, 2001; Curhan et al,1993). In studies that have established these relationships, this contribution was closely associated with the consumption of fruits and vegetables which contain other beneficial compounds for health ( $\mathrm{He}$ and $\mathrm{Mac}$ Gregor, 2008). WHO (2005) recommends increasing dietary potassium intake to lower blood pressure and reduce the risk of cardiovascular disease, stroke and coronary heart disease in adults. 
Table 1: Some chemical properties of cork oak varieties.

\begin{tabular}{cccc}
\hline Samples & Moisture \% & Titratable acidity $\left(\mathbf{1 0}^{-\mathbf{3}} \mathbf{~ m m o l . L}^{\mathbf{- 1}}\right)$ & Formol index \\
\hline HuA & $50.99 \pm 0.07$ & 5.6 & $4.66 \pm 0.41$ \\
HuS & $49.12 \pm 0.08$ & 5.2 & $4.11 \pm 0.14$ \\
HuN & $49.91 \pm 0.19$ & 5.7 & $4.61 \pm 0.29$ \\
KeA & $40.83 \pm 0.12$ & 7.1 & $6.51 \pm 0.29$ \\
KeS & $38.31 \pm 0.14$ & 6.8 & $6.17 \pm 0.05$ \\
KeN & $39.13 \pm 0.21$ & 7.1 & $6.48 \pm 0.53$ \\
\hline
\end{tabular}

HuN - fruit hull of Nefza, HuA - fruit hull of Ain drahem, HuS- fruit hull of Sejnan

$\mathrm{KeN}-$ fruit kernel of Nefza, KeA - kernel of Ain drahem, KeS - fruit kernel of Sejnan

Table 2: Mineral content of acorn cork oak expressed as $\mathrm{mg} / \mathrm{kg}$ of fresh mater.

\begin{tabular}{ccccc}
\hline & & & \\
\hline Minerals & HuA & HuS & KeA & KeS \\
\hline Copper & $4.49 \pm 0.06$ & $62.30 \pm 7.20$ & $3.60 \pm 0.12$ & $3.35 \pm 0.03$ \\
Iron & $27.94 \pm 3.20$ & $19.41 \pm 2.41$ & $10.62 \pm 1.20$ & $13.98 \pm 2.16$ \\
Manganese & $27.14 \pm 2.13$ & $89.10 \pm 7.36$ & $11.64 \pm 1.02$ & $9.04 \pm 0.86$ \\
Zinc & $9.22 \pm 1.06$ & $11.86 \pm 2.41$ & $5.37 \pm 0.52$ & $7.26 \pm 0.72$ \\
Calcium & $1396 \pm 676$ & $1636 \pm 846$ & $23.85 \pm 3.12$ & $25.01 \pm 2.12$ \\
Magnesium & $781.6 \pm 37.1$ & $784.65 \pm 54.10$ & $453.23 \pm 43.12$ & $476 \pm 43$ \\
Sodium & $504.95 \pm 27.10$ & $691.68 \pm 42.20$ & $214.16 \pm 23.12$ & $228.48 \pm 31.12$ \\
Potassium & $5942 \pm 483$ & $3112 \pm 347$ & $36825 \pm 870$ & $6942 \pm 880$ \\
\hline
\end{tabular}

Table 3: Bioactives extract content in hulls and kernels of cork oak.

\begin{tabular}{|c|c|c|c|}
\hline Samples & $\begin{array}{c}\text { Carotenoids } \\
\text { (mg EßC.100g-1 DM) }\end{array}$ & $\begin{array}{c}\text { Anthocyanins } \\
\left(\mathbf{m g ~ . 1 0 0 g}^{-1}\right)\end{array}$ & $\begin{array}{c}\text { Flavonoids } \\
\left(\text { mgECat.g }^{-1} \mathrm{DM}\right)\end{array}$ \\
\hline $\mathrm{HuA}$ & $30.16 \pm 0.45$ & $0.22 \pm 0.10$ & $0.20 \pm 0.02$ \\
\hline $\mathrm{HuS}$ & $13.19 \pm 0.15$ & $0.49 \pm 0.13$ & $0.27 \pm 0.03$ \\
\hline $\mathrm{HuN}$ & $20.61 \pm 0.06$ & $0.43 \pm 0.11$ & $0.19 \pm 0.06$ \\
\hline $\mathrm{KeA}$ & $6.39 \pm 1.05$ & $0.19 \pm 0.05$ & $0.35 \pm 0,05$ \\
\hline $\mathrm{KeS}$ & $5.90 \pm 0.25$ & $0.59 \pm 0.07$ & $0.49 \pm 0.07$ \\
\hline $\mathrm{KeN}$ & $7.04 \pm 0.95$ & $0.32 \pm 0.06$ & $0.38 \pm 0.02$ \\
\hline
\end{tabular}

Table 4: Antioxidant activity and total phenolic content of acorn cork oak

\begin{tabular}{|c|c|c|c|c|}
\hline \multicolumn{5}{|c|}{ Total phenolic (mg of GAE.g DM ${ }^{-1}$ ) } \\
\hline Samples & Solvent $\mathbf{S}_{1}$ & Solvent $S_{2}$ & Solvent $S_{3}$ & IC50 in $S_{2}(\mu \mathrm{g} / \mathrm{mL})$ \\
\hline $\mathrm{KeS}$ & $68.10 \pm 0.09$ & $77.11 \pm 1.20$ & $42.94 \pm 0.10$ & 6.94 \\
\hline $\mathrm{KeA}$ & $52.24 \pm 0.19$ & $66.18 \pm 1.06$ & $36.35 \pm 0.71$ & 8.80 \\
\hline $\mathrm{KeN}$ & $51.24 \pm 0.61$ & $67.37 \pm 0.13$ & $30.73 \pm 0.75$ & 8.11 \\
\hline $\mathrm{HuS}$ & $47.75 \pm 0.31$ & $757.24 \pm 0.19$ & $29.64 \pm 0.44$ & 9.94 \\
\hline $\mathrm{HuA}$ & $35.52 \pm 1.05$ & $449.52 \pm 0.15$ & $21.23 \pm 0.19$ & 10.34 \\
\hline $\mathrm{HuN}$ & $37.62 \pm 0.75$ & $551.38 \pm 1.02$ & $19.04 \pm 0.08$ & 9.90 \\
\hline
\end{tabular}

$\mathrm{S}_{1}:$ methanol / water $\left(80 / 20: \mathrm{v} / \mathrm{v} ; \mathrm{S}_{2}:\right.$ methanol / acetic acid $(99 / 1: \mathrm{v} / \mathrm{v}) ;$

$\mathrm{S}_{3}:$ ethanol / water $(50 / 50: \mathrm{v} / \mathrm{v})$

Table 5: Contents of sugars in hulls and kernels of the cork oak (\% DM; mean \pm SD, $n=3$ )

\begin{tabular}{llllll}
\hline \multicolumn{1}{c}{ Samples } & \multicolumn{3}{c}{ Sugars (\% DM) } \\
\hline & Fructose & \multicolumn{2}{c}{ Glucose } & \multicolumn{1}{c}{ Sucrose } & \multicolumn{1}{c}{ Maltose } \\
HuA & $0.54 \pm 0.04$ & $0.12 \pm 0.003$ & --- & $0.07 \pm 0.002$ & $0.73 \pm 0.05$ \\
$\mathrm{HuS}$ & $0.76 \pm 0.06$ & $0.42 \pm 0.01$ & $0.02 \pm 0.001$ & $0.07 \pm 0.003$ & $1.28 \pm 0.08$ \\
$\mathrm{KeA}$ & $3.00 \pm 0.23$ & $1.06 \pm 0.03$ & $0.06 \pm 0.001$ & $0.43 \pm 0.03$ & $4.55 \pm 0.44$ \\
$\mathrm{KeS}$ & $3.94 \pm 0.34$ & $1.50 \pm 0.05$ & $1.30 \pm 0.040$ & $0.34 \pm 0.02$ & $7.08 \pm 0.62$ \\
\hline
\end{tabular}

\section{Antioxidant Content in Quercus Suber Carotenoids}

The content of carotenoids has been quantified (Tab.3). The results concerning the hulls of acorn of the three regions studied show high levels of carotenoids (13.19 to $30.16 \mathrm{mg}$ $\left.\mathrm{E} \beta \mathrm{C} .100 \mathrm{~g}^{-1} \mathrm{DM}\right)$, kernels are less rich in carotenoids.

\section{Anthocyanins}

The anthocyanin contents of the studied acorns are low (0.05 to $0.13 \mathrm{mg} .100 \mathrm{~g}^{-1}$ ), with hulls having maximum values. The low values observed could be explained by the immature acorns studied which are collected in December. In spring, acorns stain red or orange which is accompanied by an influx of anthocyanins.
Indeed, light, temperature, wind and humidity are factors involved in the rate of anthocyanins.

\section{Flavonoids}

Were present in very small quantities in all investigated samples, with higher content in kernel of acorn of Sejnan $(0.49 \mathrm{mg}$ ECat. $\left.\mathrm{g}^{-1}\right)$. This is in agreement with the results of some studies conducted in Spain in 2009 by Domingues et al. on cork oak fruits that showed a content of $0.6 \mathrm{mg}$ ECat. $\mathrm{g}^{-1}$.

\section{Total Phenolic Content}

The total polyphenol contents of the extracts obtained by the three solvents $S_{1}, S_{2}$ and $S_{3}$ are listed in Table 4. Significant 
differences were observed, the amounts of total phenolics in cork oak fruits extracts for different parts of cultivars show that the methanol $1 \%$ acetic acid provide the highest levels varied widely, ranging from 77 to $49 \mathrm{mg}$ of GAE.g ${ }^{-1}$ DM. The lowest levels of total polyphenols were recorded for the extracts obtained from ethanol/water (42.9 to $19 \mathrm{mg}$ of GAE. $\mathrm{g}^{-1} \mathrm{DM}$ ). This study reported the potential effects of extracting solvent on antioxidant activity estimations for acorns. The methanol $1 \%$ acetic acid is the recommended solvent to prepare antioxidant extracts from acorns samples. We observe that for all the extraction solvents used, the kernel has higher polyphenol contents that the hulls. The highest content of polyphenols was obtained from Sejnan plant extract. Additional research is required to investigate the influence of extraction solvent on the chemical composition of acorns antioxidant extracts.

\section{Evaluation of Antioxidant Activity}

The evaluation of the antioxidant capacity of the samples was carried out by determining the concentrations required to inhibit stable radical by 50\% (IC50), which are shown in Table 3. It can be noted that all the extracts showed appreciable free radical scavenging activities in the DPPH assay. However, kernel extracts $(\mathrm{IC} 50=6.94-8.11)$ inhibit $\mathrm{DPPH}^{\circ}$ radical more rapidly than hulls extracts (IC50 = $9.9-10.3$ ). This is deduced by the results obtained by comparing the IC50 (Figures 1(a) and 1(b)).

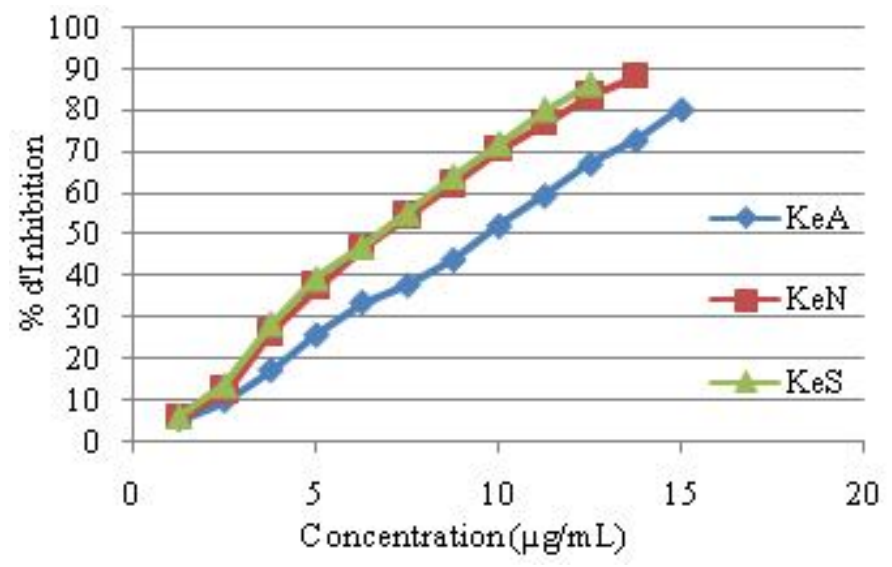

Fig.1.a : DPPH scavenging activity of methanol extracts of kernels acorns.

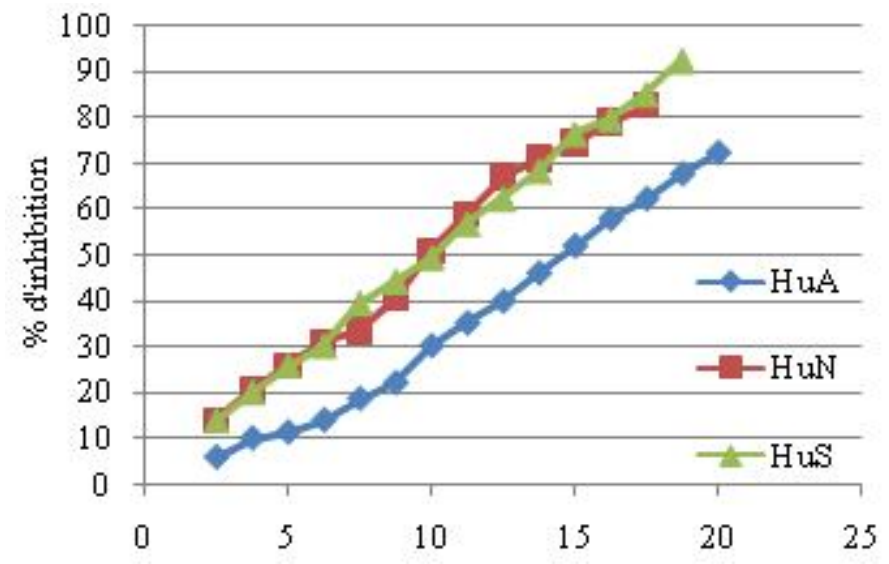

Fig.1b : DPPH scavenging activity of methanol extracts of hulls acorns.
Our results are in agreement with some previous investigations concerning types of Quercus acorns polyphenols and their antioxidant activity. Rakić et al. in 2007 have also suggested Quercus robur and Quercus cerris to be convenient nutritional components, with significant antioxidant effects (resp., IC50 = 8.04 and $\mathrm{IC} 50=8.88$ ).

Gallic acid, digallic acid and gallotannin were identified in the ethyl-acetate fraction of $Q$. acutissima acorns and caused its high antioxidant efficacy (Lee et al, 1992). The obtained results have provided further grounds for establishing $Q$. suber acorn kernels as a source for functional food preparation

\section{Correlation between Total Polyphenol Content and Anti-radical Activity}

The phenolic contents and flavonoid contents of kernel was higher than hulls, and the kernel exhibit good antioxidant activity. A positive correlation $(r=0,925)$ was found between the free radical scavenging DPPH (IC50) and the total phenolic compounds content. The polyphenols in extracts of cork oak acorns are probably responsible for the anti-radical activity of these extracts. The capacity of free radical scavenging of antioxidant does not always correlate with the capacity of antioxidation such as lipid peroxidation inhibition. The antioxidation capacity can be accessed from the extent of suppression of lipid peroxidation by antioxidant compared with that in its absence. It is determined not only by the capacity for scavenging free radicals but also by the localization of antioxidant, interaction with other antioxidants, and mobility of antioxidant at the microenvironment. These factors should be considered to understand the action and capacity of antioxidants (Niki, 2010).

\section{Sugars}

The cork oak acorns are the sweetest and most popular oak acorns, we therefore measured and identified sugars in the Tunisian variety by high performance liquid chromatography HPLC.

Soluble sugars identified and quantified in the acorns are listed in Table 5. Fructose and glucose are the major kinds of sugar while sucrose and maltose are present in smaller quantities. The lower amounts of sucrose found in these fruits may be due to the enzymatic hydrolysis of this sugar into glucose and fructose during ripening process. The kernel of acorns contains more sugars (4.55 $\%$ to $7.08 \%$ by dry weight) than the hull (0.735 to $1.28 \%)$. Acorns grown in Sejnan have the highest sugar levels. The sugars are transformed under the action of invertase, sucrose is converted by enzymatic hydrolysis in fructose (levulose) and glucose (dextrose) at the stage of maturation. Fruits with a high invertase activity, such as prickly pear fruit, kaki or pomegranates, reach a glucose/fructose ratio near 1 (Ayaz et al, 2000). A ratio higher than 1 has been found in some wild fruits, such as wild redbilberries (Vaccinium vitis-idaea L.) or blackthorn fruits (Crataegus monogyna Jacq.), which usually have more than 3-fold more glucose than fructose (Barros et al, 2010; Souci et al, 2008). On the contrary, all oak acorns samples analyzed in this study 
showed an inverse behavior, with a ratio glucose/fructose between 0.30 and 0.55 , which means that fructose content represented twice glucose content. Moreover, this profile can be related to the intense and pleasant sweet taste of oak acorns when they are completely ripe, since fructose is the sweetest of all the naturally occurring carbohydrates (Hanover and White, 1993).

\section{CONCLUSION}

This study conducted on the fruit of the Tunisian cork oak has allowed to determine its physical and chemical characteristics and mineral composition. We observe the richness of this plant in minerals $(\mathrm{Ca}, \mathrm{K})$; it can therefore compete with wheat, rice and corn.

This plant showed the presence of phenolic compounds and showed a certain level of antioxidant activity in the kernels as well as in the hulls of acorns. It revealed the presence of four sugars, fructose and glucose being the main sugars.

The results showed that the samples with the highest levels of polyphenols have the lowest IC50. Thus, the antioxidant power of the extracts studied is mainly due to the polyphenols. Great variability in antioxidant and sugar contents of these acorns was observed depending on geographic location, stage of maturation, climate and nature of the extraction solvent.

This natural product can be used as an inexpensive source of natural antioxidants and mineral supplements, especially for food industry which is expanding fast nowadays. Further investigations such as isolation and characterization of the active compounds polyphenols and carotenoids are currently in progress.

\section{REFERENCES}

Ammar H., S. Lopez, S, Gonzalez, J.S. Assessment of the digestibility of some Mediterranean shrubs by in vitro techniques. Animal Feed Science and Technology. 2005;119: 323-331.

Ayaz F. A., Kucukislamoglu M., Reunanen M. Sugar nonvolatile and phenolic acids composition of strawberry tree (Arbutus unedo L. var. ellipsoidea) fruits. Journal of Food Composition and Analysis. 2000; 13: 171-177.

Bainbridge D.A., Use of acorns for food in California: past, present, future. Proceedings of the Symposium on Multiple-use Management of California's Hardwoods. San Luis Obispo, California. $1986 ; 453-458$.

Barros L., Carvalho A. M.; Morais J. S.; Ferreira, I. C. F. R. Strawberry-tree, blackthorn and rose fruits : Detailed characterization in nutrients an phytochemicals with antioxidant properties. Food Chemistry. 2010; 120(1): 247-254.

Bazzano L.A., He J., Ogden L.G. Loria C., Vupputuri S., Myers L., Whelton P.K. Dietary potassium intake and risk of stroke in US men and women: National Health and Nutrition Examination Survey I epidemiologic follow-up study. Stroke. 2001; 32: 1473-1480.

Brand-Williams W., Cuvelier M.E., Berset C. Use of a freeradical method to evaluate antioxidant activity", LWT-Food Science and Technology 1995; 28 (1): 25-30.

Brandis D. 1972. The Forest Flora of North West and Central India. DehraDun, India : Bishen Singh Mahendra Pal Singh. pp. 564-566.

Cantos E., Espin J., Carlos Lopez-Bote C., De La Hoz, L., Ordonez, J. A. and Tomas-Barberan, F. A. Phenolic compounds and fatty acids from acorns (Quercus spp.), the main dietary constituent of freeranged iberian pigs. Journal of Agricultural and Food Chemistry. 2003; 51: 6248-6255.
Conde E., Cadahia E., Garcia-Vallejo M.C., Fernandez de Simon B. Polyphenolic Composition of Quercus Suber Cork from Different Spanish Provenances. J. Agric. Food Chem. 1998; 46: 31663171 .

Curhan G.C., Willett W.C., Rimm E.B., Stampfer M.J. A prospective study of dietary calcium and other nutrients and the risk of symptomatic kidney stones. N Engl J Med. 1993; 328: 833838 .

Garcia-Saura M.F., Galisteo M., Villar I.C., Bermejo A., Zarzuelo A., Vargas F., Duarte J., Effects of chronic quercetin treatment in experimental renovascular hypertension. Mol. Cell Biochem. 2005; 270: 147-155.

Hanover, L. M., White, J. S. Manufacturing, composition, and application of fructose. Journal of Clinical Nutrition. 1993; 58: 724 -732.

He F.J., MacGregor G.A. Beneficial effects of potassium on human health. Physiol Plant. 2008; 133: 725-35.

Houston MC., Harper KJ. Potassium, magnesium, and calcium: their role in both the cause and treatment of hypertension. J Clin Hypertens (Greenwich). 2008; 10: 3-11.

Jevtovic' M. 1980. Pelagic'ev narodni uc $\mathrm{uc}^{2}$ itelj. Beograd, Serbian : Sloboda Beograd

Lanham-New S.A. The balance of bone health: tipping the scales in favor of potassium-rich, bicarbonate-rich foods. J. Nutr. 2008; 138: $172 \mathrm{~S}-177 \mathrm{~S}$.

Lee M. H., Jeong J. H., Oh M. J. Antioxidative activity of gallic acid in acorn extract. Han'guk Yongyang Siklyong Hakhoechi. 1992; $21: 693-700$.

Majhenic L., Kerget M.S., Knez, Z. Antioxidant and antimicrobial activity of guarana seed extracts. Food Chemistry. 2007; 104: 1258-1268.

Natividade J.V. 1956. Subériculture, the Portuguese cork-oak growing. Nancy, France: French ed. E.N.E.F. p. 303.

Niki E. Assessment of antioxidant capacity in vitro and in vivo, Free Radic. Biol. Med. 2010; 49: 503-515.

OMS. 2005. Preventing chronic disease : a vital investment. Organisation mondiale de la Santé. Genève

Özcan T. ; Bayçu G. Some elemental concentrations in the acorns of turkish quercus 1. (fagaceae) taxa Pak. J. Bot. 2005; 37(2): 361371.

Patarra João Daniel Domingues. 2009. Evaluation of the in vitro biological activities of extracts from Carob tree and Mediterranean oaks. Mestrado. Faculdade de Ciências e Tecnologia, Universidade do Algarve.

Prior RL, Gu L. Occurrence and biological significance of proanthocyanidins in the American diet. Phytochemistry. 2005; 66: 22642280 .

Rakić S., Petrovic S., Kukic J., Jadranin M., Tesevic V., Povrenovic D., Siler-Marinkovic S. Influence of thermal treatment on phenolic compounds and antioxidant properties of oak acorns from Serbia. Food Chemistry. 2007; 104: 830 - 834.

Rodríguez-Estévez A. García Martínez V, Mata Moreno C. Perea Muñoz J.M ; Gómez Castro, A.G. Dimensiones Y Características Nutritivas De Las Bellotas De Los Quercus De La Dehesa. Arch. Zootec. 2008; 57: 1-12.

Rodriguez J, Olea-Azar C, Cavieres C, Norambuena E, Delgado-Castro T, Soto-Delgado J, Araya-Maturana R. Antioxidant properties and free radical-scavenging reactivity of a family of hydroxynaphthalenones and dihydroxyanthracenones. Bioorg. Med. Chem. 2007; 15: 7058-7065.

Rousseff R.L., Martin S.F., Youtsey C.O. Quantative Survery of Narirutin, Naringein, Hesperidin and Neohesperidin in Citrus. Journal of Agricultural and Food Chemistry. 1987; 35: 1027-1030.

Sies H. Polyphenols and health: update and perspectives. Arch Biochem Biophys 2010; 501: 2-5.

Sijelmassi A. 1993. Les plantes médicinales du Maroc. Casablanca, Maroc : 3rd Edition Fennec. p.285.

Singleton V L., Rossi Jr. J A. Colorunetry of total phenolics with phosphomolybdic phosphotungstic acid reagents. Amer. J. Enol. Viticult. 1965; 16: 144-58. 
Souci S. W., Fachmann W., Kraut H. 2008. Food composition and nutrition tables. Stuttgart, Germany: 7rd ed. Medpharm Scientific Publishers.

Swain T., Hillis W. E. The Phenolic Constituents of Prunus domestica. Journal of the Science of Food and Agriculture. 1959; 10: 6368 .

Tucakov J. Lečenje Biljem, Fitoterapija. Beograd, Jugoslavija Izdavačko preduzeće Rad Beograd. 1971; 402 : 535-537.

Tsuda T., Ueno Y., Yoshikawa T., Kojo H., Osawa T. Microarray profiling of gene expression in human adipocytes in response to anthocyanins. Biochemical Pharmacology. 2006; 71: 1184-1197.

Twidwell E.K., Wanger J.J., Thiex Nancy J. 2002. use a microwave oven to determine moisture content of forages. ExEx 8070.

Zhishen J., Mengcheng T., Jinming W. The determination of flavonoid contents in mulberry and their scavenging effects on superoxide radicals. Food Chem. 1999; 64: 555-559.
Yen G. C.; Duth P. D. Scavenging effect of methanolic extracts of peanut hulls on free radical and active-oxygen species. J. of Agric. And Food chem. 1994; 42 : 629-632.

\section{How to cite this article:}

Belghith S.I., Abidi H., Trabelsi-Ayadi M., Chérif J. K. Study of Physicochemicals Characteristics and Antioxidant Capacity of Cork Oak Acorns (Quercus Suber L.) grown in Three Regions in Tunisia. J App Pharm Sci, 2015; 5 (04): XXX-XXX 